\title{
Enalapril protects against myocardial ischemia/reperfusion injury in a swine model of cardiac arrest and resuscitation
}

\author{
GUOXING WANG ${ }^{1}$, QIAN ZHANG ${ }^{2}$, WEI YUAN ${ }^{2}$, JUNYUAN WU ${ }^{2}$ and CHUNSHENG LI $^{2}$ \\ ${ }^{1}$ Department of Emergency Medicine, Beijing Friendship Hospital, Capital Medical University, Beijing 100050; \\ ${ }^{2}$ Department of Emergency Medicine, Beijing Chao-Yang Hospital, Capital Medical University, Beijing Key Laboratory \\ of Cardiopulmonary Cerebral Resuscitation (NO.BZ0370), Beijing 100020, P.R. China
}

Received June 30, 2015; Accepted September 6, 2016

DOI: $10.3892 /$ ijmm.2016.2737

\begin{abstract}
There is strong evidence to suggest that angiotensin-converting enzyme inhibitors (ACEIs) protect against local myocardial ischemia/reperfusion (I/R) injury. This study was designed to explore whether ACEIs exert cardioprotective effects in a swine model of cardiac arrest (CA) and resuscitation. Male pigs were randomly assigned to three groups: sham-operated group, saline treatment group and enalapril treatment group. Thirty minutes after drug infusion, the animals in the saline and enalapril groups were subjected to ventricular fibrillation ( $8 \mathrm{~min}$ ) followed by cardiopulmonary resuscitation (up to $30 \mathrm{~min}$ ). Cardiac function was monitored, and myocardial tissue and blood were collected for analysis. Enalapril pre-treatment did not improve cardiac function or the 6-h survival rate after $\mathrm{CA}$ and resuscitation; however, this intervention ameliorated myocardial ultrastructural damage, reduced the level of plasma cardiac troponin I and decreased myocardial apoptosis. Plasma angiotensin (Ang) II and Ang-(1-7) levels were enhanced in the model of CA and resuscitation. Enalapril reduced the plasma Ang II level at 4 and $6 \mathrm{~h}$ after the return of spontaneous circulation whereas enalapril did not affect the plasma Ang-(1-7) level. Enalapril pre-treatment decreased the myocardial mRNA and protein expression of angiotensin-converting enzyme (ACE). Enalapril treatment also reduced the myocardial ACE/ACE2 ratio, both at the mRNA and the protein level. Enalapril pre-treatment did not affect the upregulation of ACE2, Ang II type 1 receptor (AT1R) and MAS after CA and resuscitation. Taken together, these findings suggest that enalapril
\end{abstract}

Correspondence to: Dr Guoxing Wang, Department of Emergency Medicine, Beijing Friendship Hospital, Capital Medical University, 95 Yong'an Road, Xicheng, Beijing 100050, P.R. China

E-mail: 13520240749@163.com

Professor Chunsheng Li, Department of Emergency Medicine, Beijing Chao-Yang Hospital, Capital Medical University, 8 Worker's Stadium South Road, Beijing Key Laboratory of Cardiopulmonary Cerebral Resuscitation (NO.BZ0370), Chao-yang, Beijing 100020, P.R. China E-mail: lcscyyy@163.com

Key words: angiotensin-converting enzyme inhibitor, cardiac arrest, resuscitation, pig, ischemia/reperfusion protects against ischemic injury through the attenuation of the ACE/Ang II/AT1R axis after CA and resuscitation in pigs. These results suggest the potential therapeutic value of ACEIs in patients with $\mathrm{CA}$.

\section{Introduction}

Sudden cardiac arrest (CA) is a major burden on health care in the US, with estimates ranging from 200,000 to 500,000 patients who experience out-of-hospital CA each year (1). The median rate of survival in adults following hospital discharge is approximately $6.7 \%$ in the US (2). It has been widely accepted that cardiopulmonary resuscitation (CPR) is an important first aid technique for CA. A 9-year retrospective cohort study of 5,958 patients receiving emergency medical service (EMS)-initiated resuscitation demonstrated that $16.8 \%$ survived at hospital discharge. Of those individuals discharged, 5-year survival was better in those who had received percutaneous coronary intervention (3). Notably, a recent randomized controlled trial has demonstrated that mild therapeutic hypothermia for $12-24 \mathrm{~h}$ improves neurologic recovery and survival after CA (4). However, even after successful CPR and therapeutic hypothermia treatment, myocardial tissue may still suffer from severe ischemia/reperfusion (I/R) injury. In many patients who initially achieve return of spontaneous circulation (ROSC) after CA, subsequent morbidity and mortality is caused by cardiac ischemia that accompanies prolonged cardiac dysfunction (5). This disease is known as post-cardiac arrest syndrome (PCAS) (5), which is a serious threat to patient health. A better understanding of the cellular and molecular mechanisms responsible for myocardial ischemia may assist in the development of more efficient treatment strategies for PCAS.

The renin-angiotensin-aldosterone system (RAAS) is an endogenous hormonal cascade that functions in the homeostatic control of arterial pressure, extracellular volume and tissue perfusion (6). Currently, blockade of the RAAS with angiotensin-converting enzyme inhibitors (ACEIs) or angiotensin II type 1 receptor (AT1R) blockers (ARBs) has been widely used as a treatment strategy in the management of patients with hypertension, acute myocardial infarction, chronic systolic heart failure, stroke and diabetic renal disease (6). However, these drugs are also associated with adverse reactions, such as hypotension (6). Following 
myocardial I/R injury, the cardioprotective effects of ACEIs have been well established (7). ACEIs are capable of acutely limiting myocardial injury and necrosis in models of permanent coronary artery occlusion. The mechanisms responsible for this cardioprotection include reductions in myocardial oxygen supply/demand, inhibition of bradykinin metabolism, increased prostaglandin synthesis and attenuated inflammatory responses (8). However, there is limited data regarding the application of ACEIs or ARBs in a model of CA and resuscitation, which features complex pathophysiological changes such as brain ischemia and renal ischemia $(9,10)$. Furthermore, there is concern that blockade of the RAAS reduces perfusion pressure, which may attenuate the beneficial effects of resuscitation.

Thus, we performed this study in order to examine the effects of enalapril pre-treatment on myocardial injury in a swine model of CA and resuscitation. We examined the effects of enalapril infusion on myocardial ultrastructure, hemodynamics and RAAS system activation, including the plasma levels of angiotensin (Ang) II and Ang-(1-7). Finally, the effects of enalapril pre-treatment on the mRNA and protein levels of angiotensin-converting enzyme (ACE), AT1R, ACE2 and MAS were evaluated in swine myocardial tissue.

\section{Materials and methods}

Animals. Inbred, male, Landrace miniature piglets aged 11-13 months, with an average weight of $30 \pm 2 \mathrm{~kg}$, were used as previously described (11). All procedures were performed in accordance with the Animal Care Guidelines of the Institutional Animal Care and Use Committee of Capital Medical University (Beijing, China) as well as the Utstein-style guidelines (12). The experimental protocol was also approved by the Committee on the Ethics of Animal Experiments of Capital Medical University. All animals were housed in a dedicated, pathogen-free environment in the Capital Medical University animal facility. Animals were fed standard chow and had free access to water.

Groups, anesthesia and ventilation. The pigs were randomly assigned to three groups: the sham-operated group (sham group, $\mathrm{n}=8$ ), the experimental CA-resuscitation + saline $(0.9 \% \mathrm{NaCl})$ group (saline group, $\mathrm{n}=12)$ and the experimental CA-resuscitation + enalapril group (enalapril group, $n=12$ ). On the experimental day, anesthesia was induced by an intramuscular injection of midazolam $(0.5 \mathrm{mg} / \mathrm{kg})$ followed by an injection of propofol $(1.0 \mathrm{mg} / \mathrm{kg}$ via an ear vein). The animals were anesthetized with an intravenous infusion of sodium pentobarbital $(8 \mathrm{mg} / \mathrm{kg} / \mathrm{h})$ to maintain favorable surgical anesthesia. The chest and back were thoroughly shaven to allow for direct contact of the paddles used for defibrillation during CPR immediately following the induction of anaesthesia.

An endotracheal tube (6.5-mm internal diameter) was used as an ordinary endotracheal tube. The tube was connected to a Servo Ventilator (Servo 900C; Siemens, Munich, Germany) with an $\mathrm{FiO}_{2}$ of 0.21 . All the animals were intubated and mechanically ventilated with room air using a tidal volume of $12 \mathrm{ml} / \mathrm{kg}$ and a respiratory frequency of 12 breaths/min. Respiratory frequency was adjusted to maintain end-tidal $\mathrm{pCO}_{2}$ between 35 and $40 \mathrm{mmHg}$, which was continuously monitored using an infrared $\mathrm{CO}_{2}$ analyzer $\left(\mathrm{CO}_{2} \mathrm{SMO}\right.$ Plus monitor; Respirometric Inc., Murrysville, PA, USA).

Preparation and monitoring. Acetated Ringer's solution $(30 \mathrm{ml} / \mathrm{kg}$ ) was infused via an ear vein to compensate for fluid loss during the first hour of preparation. During the procedure, $2.5 \%$ glucose-electrolyte solution $(8 \mathrm{ml} / \mathrm{kg} / \mathrm{h})$ was continuously infused. A Swan-Ganz catheter ( $7 \mathrm{Fr}$; Edwards Life Sciences, Irvine, CA, USA) was inserted into the pulmonary artery via the right external femoral vein for cardiac output (CO) measurement (13). Electrocardiogram and hemodynamic parameters were monitored using the M1165 monitoring system (Hewlett-Packard, Palo Alto, CA, USA). Self-adhesive defibrillation electrodes were positioned on the chest wall. Coronary perfusion pressure (CPP) was calculated as the difference, measured at the end of each minute of precordial compression, between decompression diastolic aortic and time-coincident right-atrial pressure.

Experimental procedure. Experimental ventricular fibrillation (VF) in pigs was induced in the saline and enalapril groups, but not in the sham group, as described previously (11). Pure enalapril (E6888) was purchased from Sigma-Aldrich (St. Louis, MO, USA). Following the surgical preparations described above, baseline measurements and blood samples were obtained. Then, the animals were intravenously infused with enalapril solution $(0.2 \mathrm{mg} / \mathrm{kg})$ or an equal volume of saline $30 \mathrm{~min}$ prior to VF induction. This dose was selected based on data from a previous study (14).

Successful VF was induced using a method described in previous study from our laboratory (15). A temporary pacemaker conductor was inserted into the right ventricle through the right sheathing canal and connected to an electrical stimulator (GY-600A; Kaifeng Huanan Equipment Co., Ltd., Kaifeng, China). The electrical stimulator was programmed in the S1S2 mode (300/200 msec, $40 \mathrm{~V}, 8: 1$ proportion and $10 \mathrm{msec}$ step length) to provide a continuous electrical stimulus until the occurrence of VF. Ventricular fibrillation was defined as an electrocardiogram showing waveforms corresponding to $\mathrm{VF}$ and a rapid decline in mean arterial pressure (MAP) toward zero (16).

Mechanical ventilation was stopped after successful VF induction. At $8 \mathrm{~min}$ post VF induction, monophasic electrical shock was attempted, beginning at $3 \mathrm{~J} / \mathrm{kg}$. If the initial defibrillation shock failed, energy was increased by $1 \mathrm{~J} / \mathrm{kg}$ increments for subsequent defibrillation shocks. If the first defibrillation was unsuccessful, CPR was performed for $2 \mathrm{~min}$ and the second defibrillation was induced. Manual CPR was carried out at a frequency of 100 compressions/min with mechanical ventilation at an $\mathrm{FiO}_{2}$ of $100 \%$ and a compression-to-ventilation ratio of 30:2. The swine chest was compressed to approximately one third of the anteroposterior diameter. Notably, the same CPR technician performed CPR throughout the entire study. The quality of chest compressions was controlled by a HeartStart MRx Monitor/Defibrillator with Q-CPR (Philips Medical Systems, Best, The Netherlands). The compression-to-ventilation ratio was 30:2 (17). If spontaneous circulation was not achieved after the second defibrillation attempt, CPR was continued for an additional $2 \mathrm{~min}$, and defibrillation was attempted a third time. In this manner, CPR was continued for up to $30 \mathrm{~min}$. Only the 
principal investigator, who did not take part in any resuscitation efforts, knew the treatment group assignment of each animal.

ROSC was defined as 10 consecutive min of systolic blood pressure at $50 \mathrm{mmHg}$. At $30 \mathrm{~min}$ after CPR, those animals remaining in $\mathrm{VF}$, pulseless electrical activity or asystole were considered resuscitation failures (18). After successful resuscitation, the animals were mechanically ventilated with $100 \%$ oxygen. During the next $6 \mathrm{~h}$, the animals were maintained in a surgical plane of anesthesia with an intravenous infusion of sodium pentobarbital $(8 \mathrm{mg} /$ $\mathrm{kg} / \mathrm{h}$ ). Heart rate (HR), CO, CPP and MAP were monitored in these animals hourly. Blood samples were obtained and blood plasma was prepared at $0,30 \mathrm{~min}, 1,2,4$ and $6 \mathrm{~h}$ postROSC from the sham, saline- and enalapril-treated groups. During this period, two pigs in the saline-treated group and one pig in the enalapril-treated group died due to sudden cardiac arrest. At the end of the experiments, the animals were euthanized with intravenous potassium chloride $(15 \%$, $10 \mathrm{ml}$ ). The cardiac tissue was isolated, immediately frozen in liquid nitrogen, and stored at $-80^{\circ} \mathrm{C}$.

Hemodynamic measurements. Hemodynamic parameters were measured at baseline and 0.5, 1, 2, 4 and $6 \mathrm{~h}$ after ROSC. Measured parameters included HR, CO, CPP and MAP. MAP was monitored via a right femoral arterial catheter.

Enzyme-linked immunosorbent assay (ELISA). Plasma levels of Ang II and Ang-(1-7) were measured. Plasma Ang II levels were determined using a commercial ELISA kit purchased from R\&D Systems (Minneapolis, MN, USA) and plasma Ang-(1-7) plasma levels were determined using a commercial ELISA kit purchased from BlueGene Biotech Co., Ltd. (Shanghai, China). The ELISA samples consisted of $50 \mu \mathrm{l}$ blood plasma and $50 \mu 1$ deionized water in a 96-well plate, according to the manufacturer's instructions. Optical density (OD) values $(450 \mathrm{~nm})$ were determined using a microplate reader (Tefcan M200; Tecan, Crailsheim, Germany) as previously described (19).

Measurement of plasma cardiac enzyme levels and a terminal deoxynucleotidyl transferase-mediated dUTP nick-end labeling (TUNEL) assay. According to the manufacturer's instructions, the plasma cardiac troponin I (cTNI) level was determined using a high-sensitive assay (Abbott Diagnostics, Lake Forest, IL, USA), and TUNEL assay was performed using a commercial kit (In Situ Cell Death Detection kit; Roche, Mannheim, Germany) (20).

Reverse transcription-quantitative polymerase chain reaction (RT-qPCR). RT-qPCR was performed as previously described and according to the manufacturer's protocol $(21,22)$. Total RNA was extracted from the myocardial tissue using TRIzol reagent (Invitrogen, Carlsbad, CA, USA) and then reverse transcribed into cDNA (23). For all experiments, 5 ng cDNA was subjected to RT-qPCR with a Perkin-Elmer ABI Prism 7500 sequence detection system and Power SYBR-Green PCR Master Mix (Applied Biosystems, Life Technologies, Grand Island, NY, USA). The following primers were used: ACE forward, 5'-ATC AAG CGG ATC ATA AAG AAG-3' and reverse, 5'-CAC GCT GTA GGT GGT TTC C-3'; ACE2 forward, 5'-TCT GAA TGA
CAA CAG CCT AG-3' and reverse, 5'-CAC TCC CAT CAC AAC TCC-3'; MAS forward, 5'-TAT TCC TCA TCT TCG CTA T-3' and reverse, 5'-GCC CTG GTC AGA ACA ACT-3'; AT1R forward, 5'-TCA CCT GCA TCA TCA TCT GG-3' and reverse, 5'-AGC TGG TAA GAA TGA TTA GG-3'; and GAPDH forward, 5'-GAC CCA GAA TAC CAA GTG CAG ATG TA-3' and reverse, 5'-CTG TTT CAG GAT TTA AGG TTG GAG ATT-3'. Gene expression was normalized to GAPDH. Data analysis was performed using the $2^{-\Delta \Delta \mathrm{Ct}}$ method (24).

Immunohistochemistry. Immunohistochemical staining was performed as previously described (25). Briefly, the sections were placed in $10 \mathrm{ml}$ glass centrifuge tubes and dewaxed using two changes of xylene $(3 \mathrm{ml})$ for $10 \mathrm{~min}$ at room temperature, and then rehydrated in a sequence of 100, 95, 70 and $50 \%$ graded ethanol $(3 \mathrm{ml})$. After blocking with 5\% BSA for $4 \mathrm{~h}$, the sections were incubated overnight at $4{ }^{\circ} \mathrm{C}$ with antiACE2 (1:100; Abcam, Cambridge, UK), anti-ACE (1:200; Santa Cruz Biotechnology, Dallas, TX, USA), anti-MAS (1:300; Alomone Labs Ltd., Jerusalem, Israel) or anti-AT1R (1:200; Abcam) antibodies. The sections were washed with phosphate-buffered saline (PBS) three times (5 min $\mathrm{x} 3$ ) and incubated with biotinylated secondary antibodies (1:200), followed by incubation with an avidin-biotin peroxidase complex (both from ZSGB-Biotechnology, Beijing, China). The sections incubated with normal rabbit serum (1:10) served as negative controls. Peroxidase conjugate localization was determined using 3,3'-diaminobenzidine tetrahydrochloride (DAB; Sigma, Milwaukee, WI, USA) as the chromogen, and the sections were counterstained with hematoxylin (Beijing Solarbio Science \& Technology Co., Ltd., Beijing, China). Images were captured using an IX80 microscope (Olympus, Tokyo, Japan) and analyzed using Image Pro Plus v3.0 software (Media Cybernetics, Carlsbad, CA, USA). The positive staining was defined as localization of brown staining.

Western blot analysis. Western blot analysis was performed as previously described $(26,27)$. The heart tissues were swiftly harvested, washed in PBS three times and then homogenized in lysis buffer (Tris-HCl pH 7.5, $20 \mathrm{mmol} / \mathrm{l}$; EDTA, $2 \mathrm{mmol} / \mathrm{l}$; NP-40, 1\%; and Triton X-100, 1\%) with protease inhibitors [phenylmethylsulfonyl fluoride (PMSF), $2 \mathrm{mmol} / \mathrm{l}$; leupeptin, $50 \mu \mathrm{g} / \mathrm{ml}$; aprotinin, $25 \mu \mathrm{g} / \mathrm{ml}$; pepstatin A, $10 \mu \mathrm{g} / \mathrm{ml}$; and dithiothreitol, $2 \mathrm{mmol} / \mathrm{l}$ ]. Total protein concentrations were determined using a bicinchoninic acid assay (BCA) assay (Beyotime, Haimen, China). Approximately $30 \mu \mathrm{g}$ of the homogenate samples were run on a $10 \%$ sodium dodecyl sulfate (SDS)-polyacrylamide gel, and the proteins were electrotransferred to nitrocellulose membranes (Bio-Rad Laboratories, Hercules, CA, USA). The membranes were blocked using $5 \%$ evaporated milk in PBS and then incubated for $4 \mathrm{~h}$ at room temperature with primary antibodies [anti-ACE2 (1:100; ab15348; Abcam), anti-ACE (1:200; sc-20791; Santa Cruz Biotechnology), anti-AT1R (1:100; ab18801; Abcam) and anti-MAS (1:300; AAR-013, Alomone Labs Ltd.) and $\beta$-actin (ab8226, Abcam)]. Following incubation, the blots were washed with PBS, and then incubated for $2 \mathrm{~h}$ with HRP-conjugated secondary antibodies $(1: 1,000)$. HRP signals were detected using an ECL kit (Amersham Biosciences, Little Chalfont, UK). Quantitative analysis of the data was performed by 
Table I. Physiological baseline measurements across experimental groups.

\begin{tabular}{lccc}
\hline Baseline parameters & $\begin{array}{c}\text { Sham group } \\
(\mathrm{n}=8)\end{array}$ & $\begin{array}{c}\text { Saline group } \\
(\mathrm{n}=12)\end{array}$ & $\begin{array}{c}\text { Enalapril group } \\
(\mathrm{n}=12)\end{array}$ \\
\hline Body weight $(\mathrm{kg})$ & $29.13 \pm 2.16$ & $30.63 \pm 0.92$ & $30.38 \pm 0.92$ \\
Heart rate (beats/min) & $99.00 \pm 7.44$ & $101.38 \pm 8.30$ & $100.50 \pm 10.04$ \\
Average arterial pressure (mmHg) & $103.12 \pm 5.19$ & $101.88 \pm 5.22$ & $87.00 \pm 5.81$ \\
Average pulmonary arterial pressure (mmHg) & $23.42 \pm 4.32$ & $24.13 \pm 5.24$ & $24.34 \pm 4.56$ \\
Cardiac output $(1 / \mathrm{min})$ & $2.86 \pm 0.22$ & $2.99 \pm 0.20$ & $2.99 \pm 0.19$ \\
CPP $(\mathrm{mmHg})$ & $43.5 \pm 2.4$ & $41.7 \pm 5.1$ & $42.6 \pm 6.2$ \\
\hline
\end{tabular}

Values are the means \pm SD. CPP, coronary perfusion pressure.

Table II. Outcome measures after post-resuscitation in sham, saline- and enalapril-treated groups in a swine model of myocardial I/R injury.

\begin{tabular}{lccc}
\hline Outcome measures & Sham & Saline & Enalapril \\
\hline Number of shocks & 0 & $3.7 \pm 1.5^{\mathrm{a}}$ & $2.8 \pm 0.9^{\mathrm{a}}$ \\
Energy of shock $(\mathrm{J})$ & 0 & $292.5 \pm 39.8^{\mathrm{a}}$ & $276.7 \pm 54.6^{\mathrm{a}}$ \\
Time to ROSC (min) & 0 & $5 \pm 1.8^{\mathrm{a}}$ & $5.5 \pm 1.7^{\mathrm{a}}$ \\
Number of pigs & $8(8 / 8)$ & $6(6 / 12)^{\mathrm{a}}$ & $9(9 / 12)^{\mathrm{a}}$ \\
surviving at 6 h & & & \\
\hline
\end{tabular}

Values are the means $\pm \mathrm{SD}$ or numbers (n). ${ }^{\mathrm{a}} \mathrm{P}<0.01$ vs. sham. I/R, ischemia/reperfusion; ROSC, return of spontaneous circulation.

measuring the intensity of protein band signals using Bio-Rad Image Lab Software (Bio-Rad Laboratories).

Transmission electron microscopy. The heart tissues were carefully isolated and fixed with $2.5 \%$ glutaraldehyde in $0.1 \mathrm{M}$ phosphate buffer ( $\mathrm{pH} 7.2-7.4)$ for $2 \mathrm{~h}$ at $4^{\circ} \mathrm{C}$. After washing in phosphate buffer, the tissues were post-fixed in $1 \%$ osmium tetroxide (Sigma-Aldrich, Shanghai, China) in $0.1 \mathrm{M}$ phosphate buffer for $2 \mathrm{~h}$. The tissues were dehydrated in a graded ethanol series, infiltrated with propylene oxide, embedded in epoxy resin and sliced into ultrathin sections $(1 \mu \mathrm{m})$. After double-staining with uranyl acetate (Spectrum Chemical Manufacturing Corp., Shanghai, China) and lead citrate (Sigma-Aldrich, Shanghai, China), electron microphotographs were captured using a transmission electron microscope (H-7650; Hitachi, Tokyo, Japan).

Statistical analysis. The results are expressed as the means \pm SD. Differences at various time-points within groups were compared with a repeated measures analysis of variance (ANOVA) followed by a Tukey post-hoc test. Continuous variables were adjusted to a normal distribution and equal variances were compared using the Kolmogorov-Smirnov test and homogeneity of variance test. Survival rate comparisons were performed using Chi-square analysis. $\mathrm{P}<0.05$ was considered to indicate a statistically significant difference.

\section{Results}

Enalapril does not improve survival rates in a swine model of $C A$ and resuscitation. There were no significant differences in baseline parameters (including body weight, HR, average arterial pressure, average pulmonary arterial pressure and $\mathrm{CO}$ ) among the sham, saline- and enalapril-treated groups (Table I). Moreover, there were no significant differences in the number of defibrillation shocks, shock energy and outcome between enalapril-treated pigs and saline-treated pigs $(\mathrm{P}>0.05)$ (Table II).

Effects of enalapril on hemodynamic indices in a swine model of $C A$ and resuscitation. We measured hemodynamic indices in the sham, saline- and enalapril-treated groups. Resuscitation significantly boosted HR (Fig. 1A) and MAP (Fig. 1C), but reduced $\mathrm{CO}$ (Fig. 1B) and $\mathrm{CPP}$ (Fig. 1D). Enalapril treatment did not change the HR, CO or CPP (Fig. 1A, B and D). However, enalapril treatment exhibited a marked blood pressure-lowing effect, partly inhibiting the enhancement of MAP at 4 and $6 \mathrm{~h}$ post-ROSC (Fig. 1C).

Enalapril ameliorates I/R-induced myocardial injury in a swine model of $C A$ and resuscitation. The effects of enalapril treatment on ultrastructural changes in the myocytes are shown in Fig. 2A. Transmission electron micrographs showed that acute CA and resuscitation resulted in immediate and serious injury to the myocardium of animals in the saline group. The myocytes in the saline group exhibited gigantic vacuoles, disintegration of myofibrils, severe fraying of intercellular organelles and considerable Z-band disruption. Moreover, deranged cristae and significant swelling were observed in mitochondria. By contrast, these injuries were less severe in the myocardium of animals in the enalapril-treated group. In addition, the results of the TUNEL assay showed that myocardial apoptosis in the saline group was markedly induced by CA-resuscitation, an effect that was reversed by enalapril treatment (Fig. 2B). The plasma levels of cTNI, an enzymatic marker for acute myocardial infarction and cardiac cell death, were also markedly enhanced in the saline group at 2 and $6 \mathrm{~h}$ after ROSC (Table III). Enalapril treatment significantly inhibited the increase in plasma cTNI levels at $6 \mathrm{~h}$ after ROSC (Table III). Taken together, the findings of the present study indicate that enalapril ameliorates 

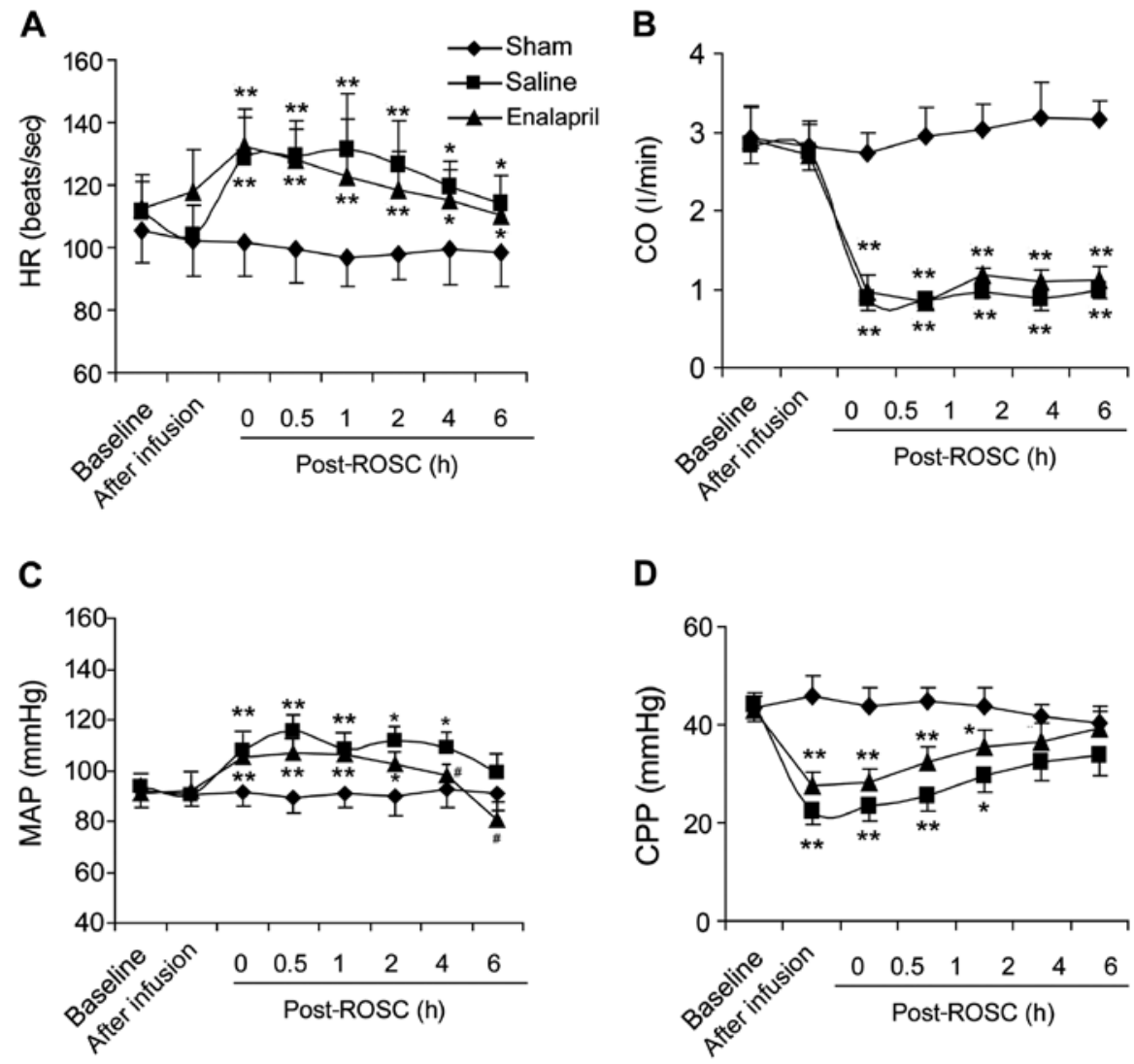

Figure 1. Cardiac functions of pigs post-resuscitation in the sham, saline- and enalapril-treated groups. (A) Heart rate (HR, beats/sec), (B) cardiac output $(\mathrm{CO}, 1 / \mathrm{min}),(\mathrm{C})$ mean arterial pressure ( $\mathrm{MAP}, \mathrm{mmHg}$ ) and (D) coronary perfusion pressure (CPP, $\mathrm{mmHg}$ ) were monitored at different time points (baseline, after infusion, $0,0.5,1,2,4$ and $6 \mathrm{~h}$ ) following restoration of spontaneous circulation (post-ROSC, h). ${ }^{*} \mathrm{P}<0.05$ and ${ }^{* *} \mathrm{P}<0.01$ vs. sham group; ${ }^{*} \mathrm{P}<0.05$ vs. saline group. $\mathrm{n}=8-12 /$ group initially.
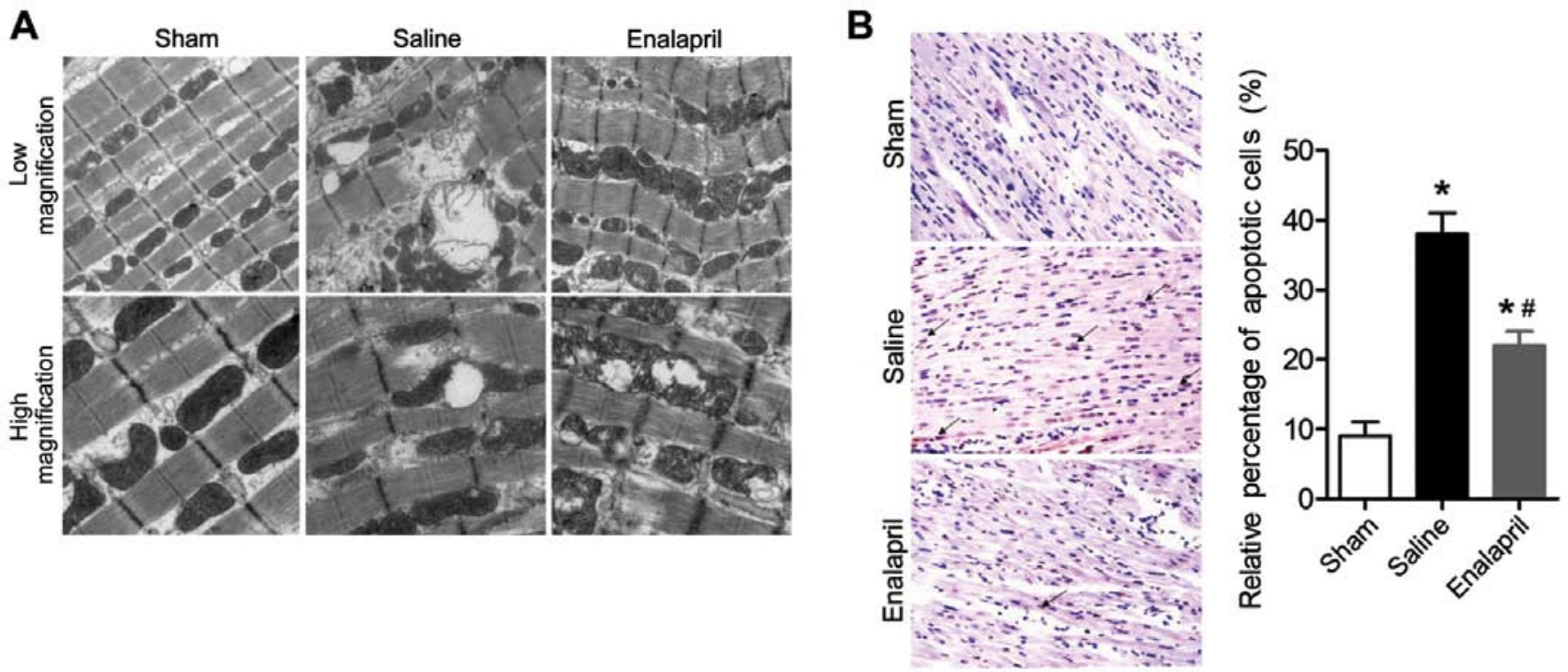

Figure 2. Enalapril decreases myocardial injury in a swine model of cardiac arrest (CA) and resuscitation. (A) Ultrastructural changes in myocytes of sham, saline- and enalapril-treated groups were revealed by transmission electron microscope analysis at low (x20,000) and high (x40,000) magnifications. (B) Representative images and quantitative analysis of myocardial apoptosis. The black arrows indicate apoptotic cells. ${ }^{*} \mathrm{P}<0.05$ vs. sham group; ${ }^{\text {"}} \mathrm{P}<0.05$ vs. saline group. $n=6-9 /$ group. At least ten fields were counted for every sample for quantitative analysis.

I/R-induced myocardial injury in a swine model of CA and resuscitation.
Enalapril decreases plasma Ang II levels but not Ang-(1-7) levels in a swine model of $C A$ and resuscitation. There was 
Table III. Plasma cTNI levels in sham, saline- and enalapril-treated groups in a swine model of myocardial I/R injury.

\begin{tabular}{cccc}
\hline Time after ROSC & Sham & Saline & Enalapril \\
\hline 0 h after ROSC & $0.01 \pm 0.005$ & $0.01 \pm 0.003$ & $0.01 \pm 0.007$ \\
2 h after ROSC & $0.01 \pm 0.006$ & $1.99 \pm 0.74^{\mathrm{a}}$ & $2.12 \pm 0.98^{\mathrm{a}}$ \\
6 h after ROSC & $0.01 \pm 0.004$ & $4.25 \pm 1.20^{\mathrm{a}}$ & $3.17 \pm 1.05^{\mathrm{a}, \mathrm{b}}$ \\
\hline
\end{tabular}

cTNI, cardiac troponin I (ng/ml); I/R, ischemia/reperfusion; ROSC, return of spontaneous circulation. Values are the means $\pm \mathrm{SD} .{ }^{\mathrm{a}} \mathrm{P}<0.01$

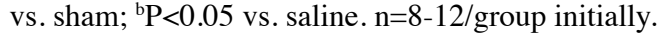

no significant difference in the baseline plasma levels of Ang II (Fig. 3A) and Ang-(1-7) (Fig. 3B) among the three groups. The plasma Ang II levels in the saline group were markedly increased at 2, 4 and $6 \mathrm{~h}$ post-ROSC (Fig. 3A). Enalapril treatment significantly reduced the plasma Ang II levels at 4 and $6 \mathrm{~h}$ post-ROSC $(\mathrm{P}<0.05)$ compared with levels in the saline group (Fig. 3A). The plasma Ang-(1-7) levels in the saline group were also increased at 4 and $6 \mathrm{~h}$ postROSC (Fig. 3B). Enalapril treatment did not reduce the plasma Ang-(1-7) levels, although there was a trend toward a reduction of Ang-(1-7) levels in the enalapril-treated pigs at 4 and $6 \mathrm{~h}$ post-ROSC (Fig. 3B).

Enalapril reduces myocardial ACE expression whereas it has no effect on ACE2 expression in a swine model of CA and resuscitation. The effects of enalapril on myocardial ACE and ACE2 expression were assessed by RT-qPCR, western blot analysis and immunohistochemistry. We found that the mRNA levels of ACE increased by $\sim 3$-fold after resuscitation in the saline group compared with that in the sham group $(\mathrm{P}<0.05)$ (Fig. 4A). Enalapril treatment inhibited this upregulation of myocardial ACE after resuscitation $(\mathrm{P}<0.05)$ (Fig. 4A). The results of western blot analysis revealed that the myocardial ACE protein level in the saline group was $\sim 2.5$-fold of that in the sham group, and enalapril suppressed this upregulation
$(\mathrm{P}<0.01)$ (Fig. 4B). Immunohistochemical analysis confirmed that ACE protein levels were increased after resuscitation and that this effect was partly inhibited by enalapril treatment $(\mathrm{P}<0.05)$ (Fig. 4C). RT-qPCR, western blot analysis and immunohistochemistry revealed that the myocardial mRNA and protein levels of ACE2 were significantly enhanced after resuscitation $(\mathrm{P}<0.05)$ (Fig. 5A-C). In contrast to the changes observed in ACE expression, enalapril treatment failed to modulate the myocardial mRNA and protein expression of ACE2 (P>0.05) (Fig. 5A-C). These data indicate that enalapril reduces myocardial ACE expression whereas it has no effect on ACE2 expression after resuscitation in swine.

Enalapril decreases the myocardial ACE/ACE2 $m R N A$ ratio in a swine model of $C A$ and resuscitation. The MRNA and protein ratios of myocardial ACE to ACE2 were determined in each group following resuscitation. The ratios of myocardial ACE/ACE2 mRNA (Fig. 6A) and protein (Fig. 6B) were significantly decreased by enalapril treatment $(\mathrm{P}<0.05)$.

Enalapril does not alter ATIR and MAS expression in a swine model of $C A$ and resuscitation. We also measured the mRNA and protein levels of AT1R and MAS in each experimental group using RT-qPCR, western blot analysis and immunohistochemistry. The mRNA level of AT1R was increased $\sim 4$-fold after resuscitation in the saline group compared with that in the sham group $(\mathrm{P}<0.01)$ (Fig. 7A). Western blot analysis also showed an increase in myocardial AT1R protein levels in the saline group $(\mathrm{P}<0.01)$ (Fig. 7B). Immunohistochemical analysis confirmed the upregulation of AT1R protein (Fig. 7C). Enalapril treatment had no effect on the upregulation of AT1R (Fig. 7A-C). Similarly, RT-qPCR, western blot analysis and immunohistochemistry revealed that the mRNA and protein levels of myocardial MAS were significantly enhanced after resuscitation $(\mathrm{P}<0.01)$ (Fig. 8). However, enalapril treatment did not modulate the mRNA or protein expression of myocardial MAS (Fig. 8). Taken together, these findings indicate that AT1R and MAS are upregulated after $\mathrm{CA}$ and resuscitation, whereas enalapril does not affect their upregulation.
A

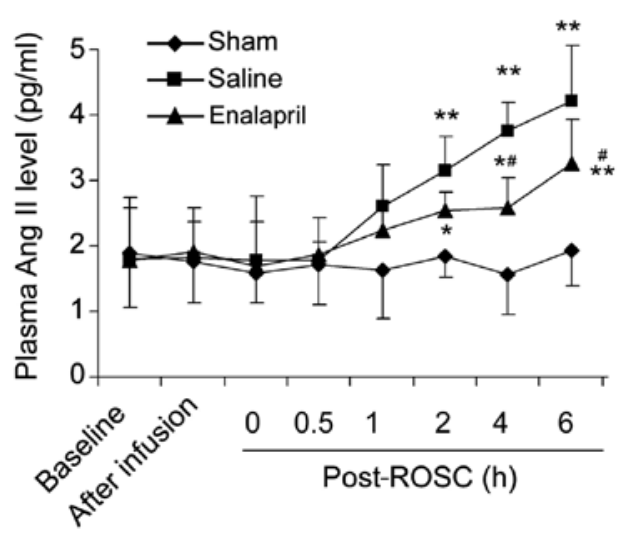

B

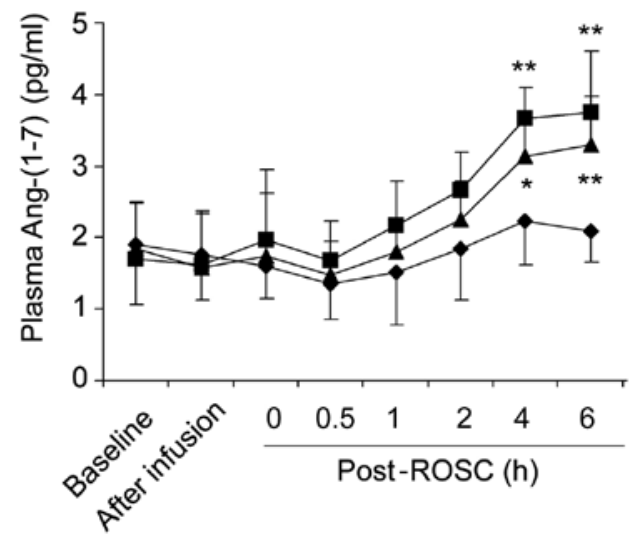

Figure 3. Plasma levels of the renin-angiotensin system components, angiotensin (Ang) II and Ang-(1-7), in a swine model of cardiac arrest (CA) and resuscitation. ELISA determination of (A) Ang II and (B) Ang-(1-7) levels at different time points (baseline, after infusion, 0, 0.5, 1, 2, 4 and 6 h) in sham, saline- and enalapril-treated groups following the return of spontaneous circulation (post-ROSC, h) were determined by ELISA. ${ }^{*} \mathrm{P}<0.05$ and ${ }^{* *} \mathrm{P}<0.01$ vs. sham group; ${ }^{\prime \prime} \mathrm{P}<0.05$ vs. saline group. $\mathrm{n}=6-9 /$ group. 

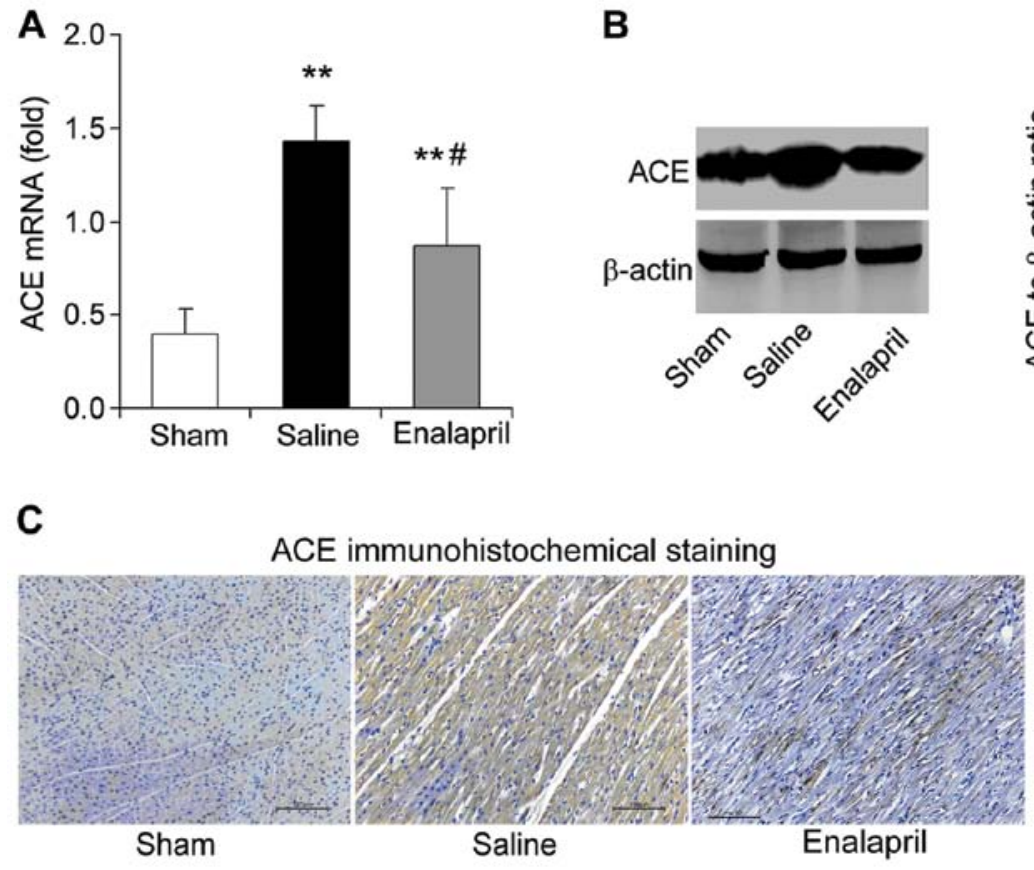

B
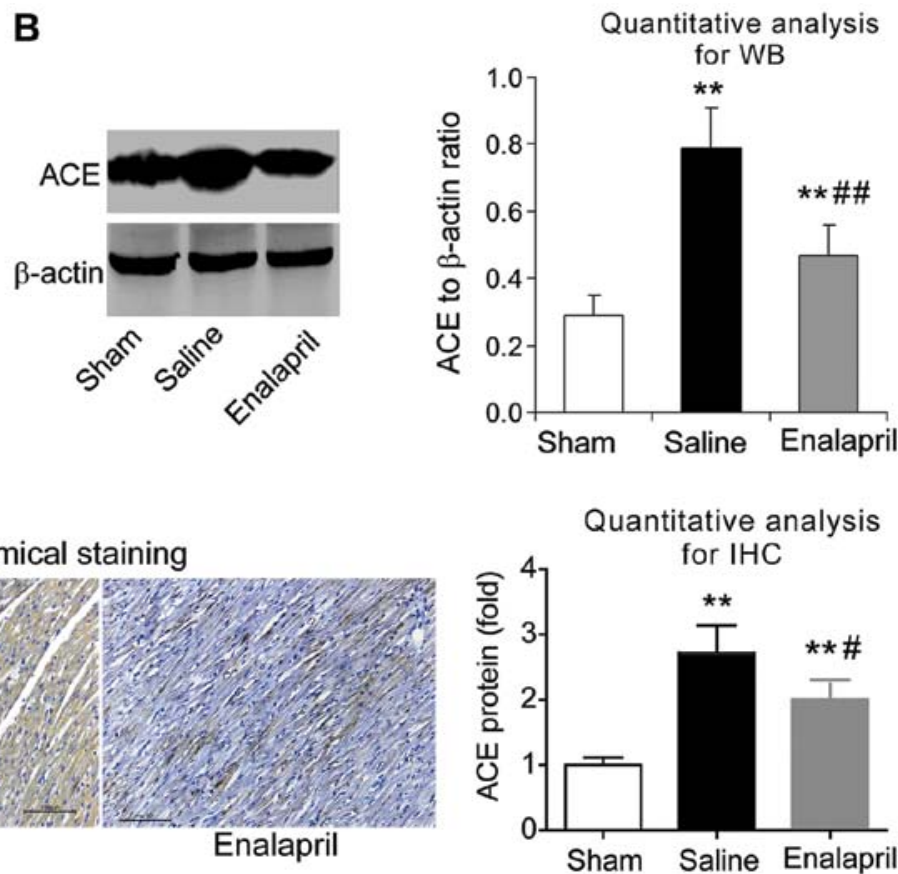

Figure 4. The mRNA and protein levels of angiotensin-converting enzyme (ACE) in myocardial tissue post-resuscitation in a swine model of cardiac arrest (CA)-resuscitation. Effects of enalapril on the mRNA and protein levels of ACE were determined using (A) RT-qPCR, (B) western blot analysis and (C) immunohistochemistry and compared with the sham and the saline-treated groups. ${ }^{*} \mathrm{P}<0.05$ and ${ }^{* * *} \mathrm{P}<0.01$ vs. sham group; ${ }^{*} \mathrm{P}<0.05$ and ${ }^{\# \#} \mathrm{P}<0.01$ vs. saline group. $\mathrm{n}=6-9 /$ group. Magnification, $\mathrm{x} 200$ in (C).

A

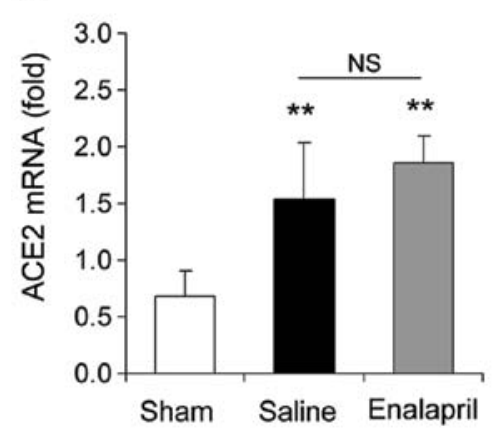

C

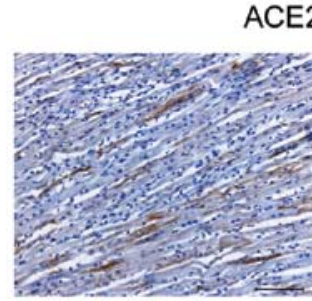

Sham
B

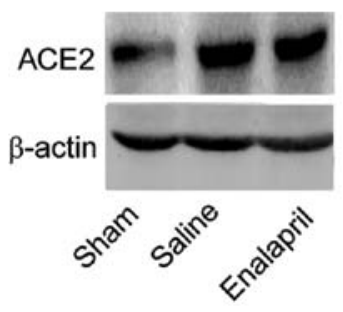

Quantitative analysis for IHC

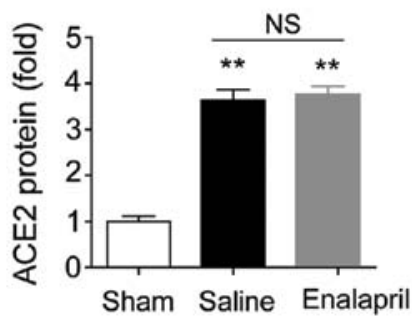

Figure 5. The mRNA and protein levels of angiotensin-converting enzyme 2 (ACE2) in myocardial tissue post-resuscitation in a swine model of cardiac arrest (CA) and resuscitation. Effects of enalapril on the mRNA and protein levels of ACE2 were determined using (A) RT-qPCR, (B) western blot analysis and (C) immunohistochemistry and compared with the sham and saline-treated groups. ${ }^{*} \mathrm{P}<0.05,{ }^{* *} \mathrm{P}<0.01$ vs. sham group. NS, no significance. $\mathrm{n}=6-9 /$ group Magnification, $\mathrm{x} 200$ in (C).

\section{Discussion}

In the present study, we demonstrated a cardioprotective role for enalapril through modulation of the RAAS in a swine model of CA and resuscitation. Although enalapril did not improve the survival rate in this model, it greatly ameliorated I/R-induced ultrastructural changes in myocytes, plasma enzyme levels and myocardial apoptosis. Additionally, the 

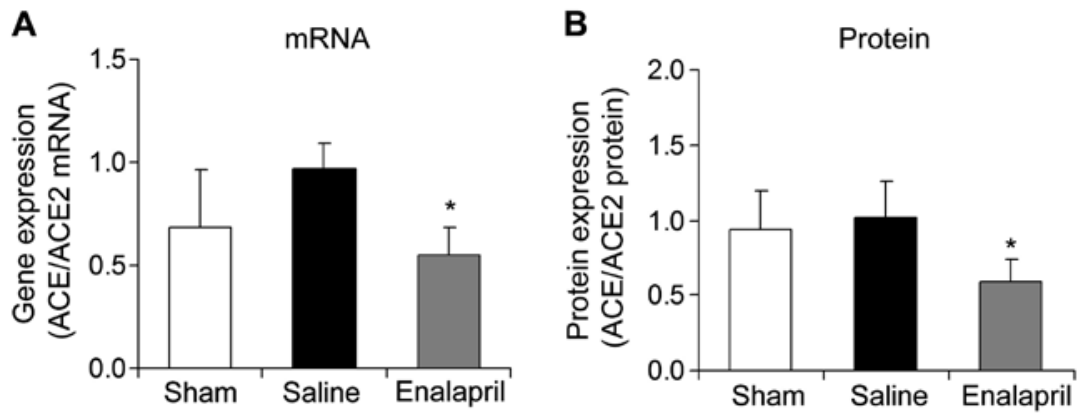

Figure 6. (A and B) Ratio of angiotensin-converting enzyme (ACE) to ACE2 mRNA and protein levels in myocardial tissue post-resuscitation in a swine model of cardiac arrest (CA) and resuscitation. ${ }^{*} \mathrm{P}<0.05$ vs. saline group. $\mathrm{n}=6-9$ /group.

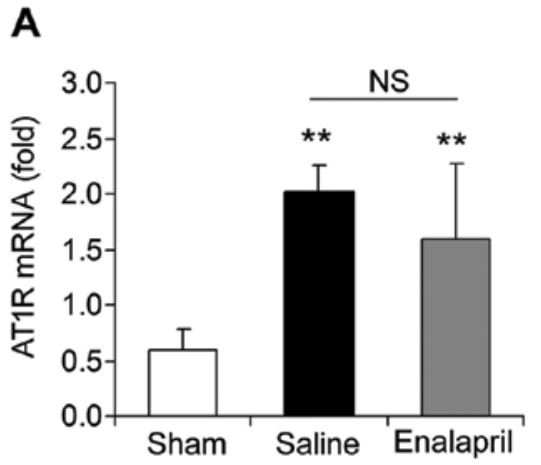

C

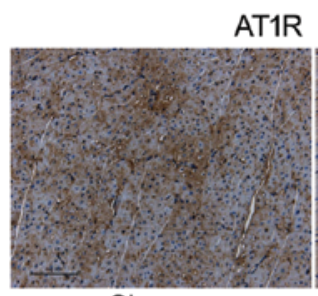

Sham
B
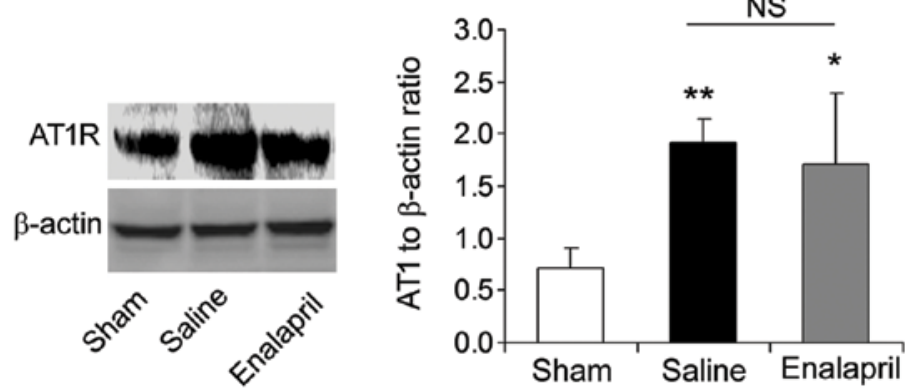

Quantitative analysis for IHC

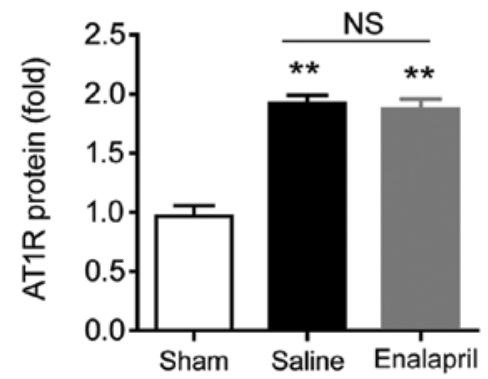

Figure 7. The mRNA and protein levels of angiotensin II type 1 receptor (AT1R) in myocardial tissue post-resuscitation in a swine model of cardiac arrest (CA)and resuscitation. Effects of enalapril on the mRNA and protein levels of AT1R were determined using (A) RT-qPCR, (B) western blot analysis and (C) immunohistochemistry, and compared with the sham and saline-treated groups. ${ }^{*} \mathrm{P}<0.05$ and ${ }^{* *} \mathrm{P}<0.01$ vs. sham group. NS, no significance. $\mathrm{n}=6-9 /$ group. Magnification, $\mathrm{x} 200$ in $(\mathrm{C})$.

enhancement of plasma Ang II levels at 4 and $6 \mathrm{~h}$ post-ROSC was significantly inhibited by enalapril pre-treatment. By contrast, enalapril pre-treatment did not affect plasma Ang-(1-7) levels. RT-qPCR, western blot analysis and immunohistochemistry assays demonstrated that enalapril pre-treatment successfully suppressed the upregulation of ACE but not ACE2 upon CA and resuscitation. Particularly, we noted that the mRNA ratio of ACE/ACE2 was also decreased by enalapril pre-treatment. Finally, enalapril did not alter the upregulation of AT1R and MAS upon CA and resuscitation. These results demonstrate, for the first time to the best of our knowledge, that pre-treatment with an ACEI protects against myocardial I/R injury post CA and resuscitation, and that inhibition of the ACE/Ang II/AT1R axis may contribute to the cardioprotective effects of enalapril in this context.

The pathophysiology of PCAS is unique from post-arrest brain injury, post-arrest myocardial dysfunction, systemic
I/R response and persistent precipitating pathology (28). Ischemic cerebral injury alone contributes significantly to the high morbidity and mortality in the resuscitated cardiac arrest patient. The myocardial dysfunction associated with PCAS is characterized largely by global hypokinesis and also, ultimately affects the success rate of resuscitation (28). The following molecular mechanisms may contribute to the pathophysiology of myocardial dysfunction in PCAS. Firstly, $\mathrm{I} / \mathrm{R}$ injury results in a large amount of oxygen free radicals which damage cell membranes and induce the necrosis and apoptosis of myocytes (29). Secondly, intracellular $\mathrm{Na}^{+}$ accumulation caused by $\mathrm{CA}$ leads to cytosolic $\mathrm{Ca}^{2+}$ overload through the reverse-mode operation of the sarcolemmal $\mathrm{Na}^{+}-\mathrm{Ca}^{2+}$ exchanger. Limiting sarcolemmal $\mathrm{Na}^{+}$entry during resuscitation from ventricular fibrillation has been shown to prevent the accumulation of excess mitochondrial $\mathrm{Ca}^{2+}$ and attenuate myocardial injury (30). Additionally, it 


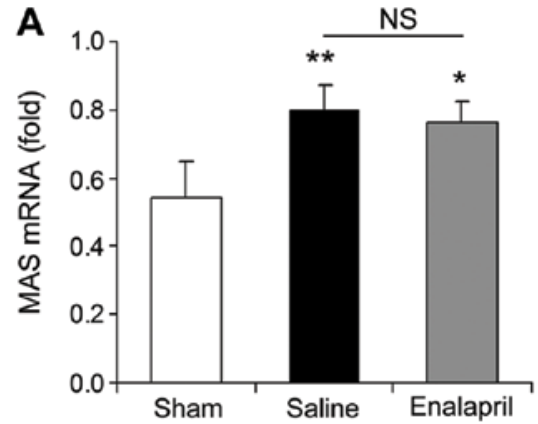

C

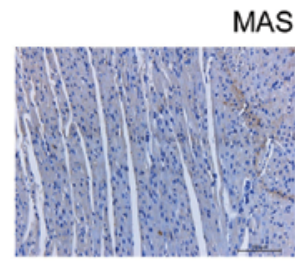

Sham
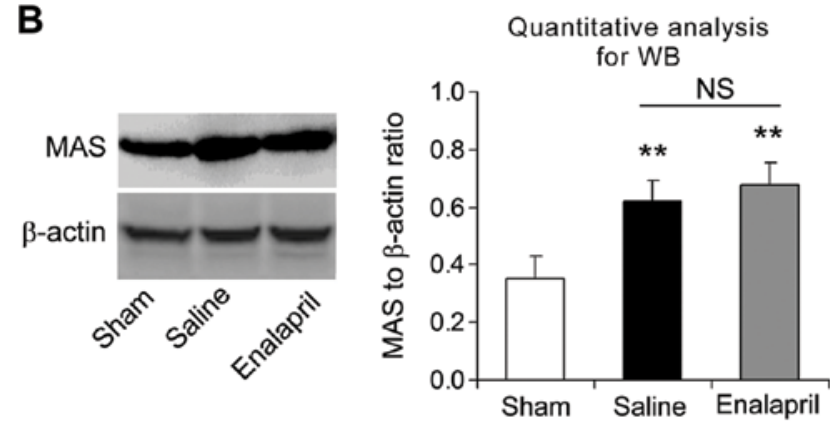

Quantitative analysis for IHC

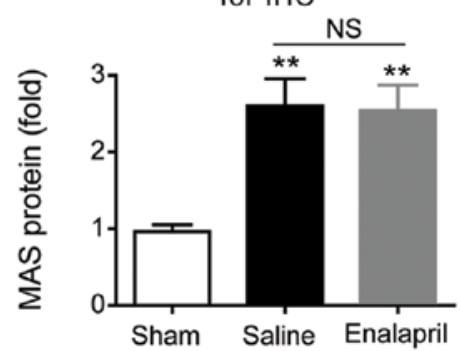

Figure 8. The mRNA and protein levels of MAS receptor in myocardial tissue post-resuscitation in a swine model of cardiac arrest (CA)and resuscitation. Effects of enalapril on the mRNA and protein levels of MAS receptor were determined using (A) RT-qPCR, (B) western blot analysis and (C) immunohistochemistry and compared with the sham and saline-treated groups. ${ }^{*} \mathrm{P}<0.05$ and ${ }^{* *} \mathrm{P}<0.01$ vs. sham group. NS, no significance. $\mathrm{n}=6-9 /$ group. Magnification, $\mathrm{x} 200$ in $(\mathrm{C})$.

has become apparent that the endothelium participates in a host of responses elicited by I/R injury in PCAS. Both biochemical and mechanical stimulation of the endothelium elicits the production of several mediators, including endothelium-derived nitric oxide, prostaglandins, antithrombotics and anticoagulants (31).

Enalapril is a long-acting, sulphydryl-free ACEI with maximal humoral and hypotensive effects at 4-8 h, which remain detectable at $24 \mathrm{~h}$, after a single dose (32). It has been widely prescribed as an anti-hypertensive drug for many years. Previously, the beneficial effect of enalapril on myocardial ischemic injury has been confirmed in animal models of coronary artery ligation $(7,33)$. These studies showed that ACEIs limited myocardial injury and necrosis $(7,33)$. Moreover, a larger scale clinical trial demonstrated that there were significant reductions in the number of enalapril-treated patients developing myocardial infarction or unstable angina (34). Enalapril has also been shown to decrease blood markers of inflammation in patients hospitalized with ischemic symptoms (34). However, there are significant differences between the myocardial ischemic injury induced by coronary artery ligation and CA-resuscitation. Coronary artery ligation always induces local myocardial ischemic injury whereas CA-resuscitation may induce global hypoperfusion that results in acute damage to other organs, such as cerebral I/R injury and kidney I/R injury $(9,10)$. Disruption of the blood-brain barrier and the formation of brain edema after CA-resuscitation are the major factors leading to permanent brain damage (35). However, information regarding the application of ACEIs in patients with CA and resuscitation is limited. Recently, Hoyer et al provided evidence that ACE inhibition led to significantly improved myocardial contractility after prolonged CA with Bretschneider's solution (36).
In line with the findings of this study, our data demonstrated that enalapril also successfully decreased myocardial injury in a swine model of CA-resuscitation. The attenuation of ultrastructural injury, plasma cTNI levels and myocardial apoptosis were observed in the heart tissue of the enalapril-treated swine. We suggest that the cardioprotective effects of enalapril are associated with anti-apoptotic activity. Previously, the anti-apoptotic effect of ACEIs or ARBs were illustrated in left anterior descending (LAD) artery ligation-induced local myocardial ischemia $(37,38)$. To the best of our knowledge, our data provides evidence for this effect of ACEIs in a model of CA-resuscitation for the first time.

Some researchers and clinicians have suggested that ACEIs may induce hypoperfusion and therefore be harmful to the myocardium during $\mathrm{CA}$ and resuscitation $(39,40)$. For example, a case report by Bjerregaard and Jaffe found that a patient presenting for cerebral aneurysm clipping continued ACEI use on the morning of surgery, and subsequently experienced significant post-induction hypotension that culminated in CA (39). However, Zhang et al reported that enalapril did not affect coronary perfusion pressure during the resuscitation period after VF (41). Our data showed that although MAP was slightly decreased, enalapril had no detrimental effect on the survival rate post CA-resuscitation. These results suggest that blockade of the RAAS would not increase the mortality of CA. Clinical investigation has also demonstrated that there was no difference in the incidence of CA between patients treated with ACEIs and without ACEIs (2). Thus, this study supports the notion that the application of ACEIs is a promising therapy in post-resuscitation patients.

The present study further explored the potential effects of enalapril pre-treatment on the RAAS system. The RAAS is composed of a series of hormones and corresponding enzymes. 
Angiotensinogen is the precursor molecule of the RAAS and its cleavage product is Ang I, which is converted to Ang II by ACE. Ang II is the major effector of the RAAS through binding to 2 receptor subtypes, AT1R and AT2R. Most detrimental actions of Ang II on the heart are mediated by AT1 $(42,43)$. Ang-(1-7) may be catalyzed by ACE2 from Ang II and activates the MAS receptor to exert vasodilatatory, anti-angiogenic, anti-thrombotic and anti-proliferative effects (6). Thus, the balance between the ACE/Ang II/AT1R axis and the ACE2/Ang-(1-7)/MAS axis elegantly modulates cardiovascular biology. An imbalance between these two axes leads to dysfunction of the RAAS, which may underlie the pathophysiology of cardiovascular disorders such as ischemic heart disease, vascular remodeling, hypertension, cardiac failure, atherosclerosis, neointima formation and chronic kidney disease. During these processes, an increased circulating level of Ang II may be a critical adverse factor. In line with previous findings (44), we observed elevations in plasma Ang II and Ang-(1-7) in the saline group; however, enalapril successfully lowered plasma Ang II levels. As a result, we hypothesize that enalapril may protect organs from Ang II-induced cellular damage by suppressing the ACE/Ang II/AT1R axis. By contrast, enalapril did not affect Ang-(1-7) levels, suggesting that ACEIs do not alter plasma Ang-(1-7) levels.

Enalapril reduced the mRNA and protein expression of $\mathrm{ACE}$, as well as the ACE/ACE2 mRNA ratio. The ratio of ACE/ACE2 in myocardial tissue is a marker of RAAS activation (45). Particularly, ACE and ACE2 often go in opposite directions in renal pathological states, and the ACE/ACE2 ratio is a convenient way to reflect this altered pattern (45). It has been demonstrated that the ACE/ACE2 ratio correlated positively with mean blood pressure, fasting blood glucose, serum creatinine, proteinuria and hemoglobin A1c, and inversely correlated with the estimated glomerular filtration rate (34). The ACE/ACE2 ratio may serve as a novel biomarker or independent risk factor relevant for the diagnosis and the prognosis of cardiorenal syndrome (46). An increased ACE/ACE2 ratio in diabetic patients with overt nephropathy suggests that RAAS activation has occurred, which may contribute to renal injury as a result of Ang II accumulation $(45,47)$. Liu et al showed that a change in the ACE/ACE2 ratio correlates with the severity of cerulein-induced acute pancreatitis in mice (48). Moreover, the ACE/ACE2 ratio is a potential biomarker for pulmonary disease (49). Consequently, the enalapril-induced attenuation of the local ACE/ACE2 ratio may ultimately contribute to the protective effects of enalapril on myocytes.

There are several limitations of this study. Firstly, we used healthy pigs in this model of CA and resuscitation; however, most humans suffering from CA are at risk of hyperglycemia, hyperlipidemia and arrhythmia. These malfunctions may affect the outcome of enalapril treatment in humans. Secondly, we selected the dose of enalapril according to the findings of previous studies and did not test other dosages and time windows for enalapril pre-treatment in the CA and resuscitation model. In fact, the dosage and time window for enalapril directly determines the therapeutic outcome. Thirdly, enalapril was administered prior to CA to illustrate the protective effects of enalapril against global ischemic injury rather than against limited myocardial tissue ischemia. Whether enalapril would still exert cardioprotective effects post-CA was not evaluated.
In conclusion, our data demonstrate that enalapril protects against myocardial I/R injury in a swine model of CA and resuscitation by suppressing the ACE/Ang II/AT1R axis. These results enhance our understanding of the cardioprotective effects of enalapril targeted against CA-induced global I/R injury.

\section{Acknowledgements}

This study was supported by the National Natural Science Foundation of China (no. 81374004).

\section{References}

1. Lerakis S, Hayek S, Arepalli CD, Thourani V and Babaliaros V: Cardiac magnetic resonance for paravalvular leaks in post-transcatheter aortic valve replacement. Circulation 129: e430-e431, 2014.

2. Go AS, Mozaffarian D, Roger VL, Benjamin EJ, Berry JD, Blaha MJ, Dai S, Ford ES, Fox CS, Franco S, et al; American Heart Association Statistics Committee and Stroke Statistics Subcommittee: Heart disease and stroke statistics - 2014 update: a report from the American Heart Association. Circulation 129: e28-e292, 2014.

3. Dumas F, White L, Stubbs BA, Cariou A and Rea TD: Long-term prognosis following resuscitation from out of hospital cardiac arrest: role of percutaneous coronary intervention and therapeutic hypothermia. J Am Coll Cardiol 60: 21-27, 2012.

4. Hypothermia after Cardiac Arrest Study Group: Mild therapeutic hypothermia to improve the neurologic outcome after cardiac arrest. N Engl J Med 346: 549-556, 2002.

5. Stub D, Bernard S, Duffy SJ and Kaye DM: Post cardiac arrest syndrome: a review of therapeutic strategies. Circulation 123: 1428-1435, 2011.

6. Paul M, Poyan Mehr A and Kreutz R: Physiology of local renin-angiotensin systems. Physiol Rev 86: 747-803, 2006.

7. Li K and Chen X: Protective effects of captopril and enalapril on myocardial ischemia and reperfusion damage of rat. J Mol Cell Cardiol 19: 909-915, 1987.

8. Sharma JN: The kallikrein-kinin system: from mediator of inflammation to modulator of cardioprotection. Inflammopharmacology 12: 591-596, 2005.

9. Kusch A,Hoff U,Bubalo G,Zhu Y,Fechner M, Schmidt-Ullrich R, Marko L, Müller DN, Schmidt-Ott KM, Gürgen D, et al: Novel signalling mechanisms and targets in renal ischaemia and reperfusion injury. Acta Physiol (Oxf) 208: 25-40, 2013.

10. Geng Y, Li E, Mu Q, Zhang Y, Wei X, Li H, Cheng L and Zhang B: Hydrogen sulfide inhalation decreases early blood-brain barrier permeability and brain edema induced by cardiac arrest and resuscitation. J Cereb Blood Flow Metab 35: 494-500, 2015

11. Guo ZJ, Li CS, Yin WP, Hou XM, Gu W and Zhang D: Comparison of shock-first strategy and cardiopulmonary resuscitation-first strategy in a porcine model of prolonged cardiac arrest. Resuscitation 84: 233-238, 2013.

12. Idris AH, Becker LB, Ornato JP, Hedges JR, Bircher NG, Chandra NC, Cummins RO, Dick W, Ebmeyer U, Halperin HR, et al; Writing Group: Utstein-style guidelines for uniform reporting of laboratory CPR research. A statement for healthcare professionals from a task force of the American Heart Association, the American College of Emergency Physicians, the American College of Cardiology, the European Resuscitation Council, the Heart and Stroke Foundation of Canada, the Institute of Critical Care Medicine, the Safar Center for Resuscitation Research, and the Society for Academic Emergency Medicine. Circulation 94: 2324-2336, 1996.

13. Wang S, Li C, Ji X, Yang L, Su Z and Wu J: Effect of continuous compressions and 30:2 cardiopulmonary resuscitation on global ventilation/perfusion values during resuscitation in a porcine model. Crit Care Med 38: 2024-2030, 2010.

14. Pereira AJ, Jeger V, Fahrner R, Djafarzadeh S, Lensch M, Takala J and Jakob SM: Interference of angiotensin II and enalapril with hepatic blood flow regulation. Am J Physiol Gastrointest Liver Physiol 307: G655-G663, 2014.

15. Gu W, Li CS, Yin WP, Hou XM, Zhang J, Zhang D and Guo Z: Expression imbalance of transcription factors GATA-3 and T-bet in post-resuscitation myocardial immune dysfunction in a porcine model of cardiac arrest. Resuscitation 84: 848-853, 2013. 
16. Zhang Q and Li C: Combination of epinephrine with esmolo attenuates post-resuscitation myocardial dysfunction in a porcine model of cardiac arrest. PLoS One 8: e82677, 2013.

17. Ji XF, Li CS, Wang S, Yang L and Cong LH: Comparison of the efficacy of nifekalant and amiodarone in a porcine model of cardiac arrest. Resuscitation 81: 1031-1036, 2010.

18. Valenzuela TD, Roe DJ, Cretin S, Spaite DW and Larsen MP: Estimating effectiveness of cardiac arrest interventions: a logistic regression survival model. Circulation 96: 3308-3313, 1997.

19. Wang P, Xu TY, Wei K, Guan YF, Wang X, Xu H, Su DF, Pei G and Miao CY: ARRB1/ $\beta$-arrestin-1 mediates neuroprotection through coordination of BECN1-dependent autophagy in cerebral ischemia. Autophagy 10: 1535-1548, 2014.

20. Wang YG, Li Y, Wang CY, Ai JW, Dong XY, Huang HY, Feng ZY, Pan YM, Lin Y, Wang BX and Yao LL: L-3-n-Butylphthalide protects rats' cardiomyocytes from ischaemia/reperfusioninduced apoptosis by affecting the mitochondrial apoptosis pathway. Acta Physiol (Oxf) 210: 524-533, 2014.

21. Wang P, Du H, Zhou CC, Song J, Liu X, Cao X, Mehta JL, Shi Y, Su DF and Miao CY: Intracellular NAMPT-NAD ${ }^{+}$-SIRT1 cascade improves post-ischaemic vascular repair by modulating Notch signalling in endothelial progenitors. Cardiovasc Res 104: 477-488, 2014

22. Ragone MI, Torres NS and Consolini AE: Energetic study of cardioplegic hearts under ischaemia/reperfusion and $\left[\mathrm{Ca}\left({ }^{2+}\right)\right]$ changes in cardiomyocytes of guinea-pig: mitochondrial role. Acta Physiol (Oxf) 207: 369-384, 2013.

23. Wang P, Xu TY, Guan YF, Zhao Y, Li ZY, Lan XH, Wang X, Yang PY, Kang ZM, Vanhoutte PM and Miao CY: Vascular smooth muscle cell apoptosis is an early trigger for hypothyroid atherosclerosis. Cardiovasc Res 102: 448-459, 2014.

24. Wang P, Xu TY, Guan YF, Tian WW, Viollet B, Rui YC, Zhai QW, Su DF and Miao CY: Nicotinamide phosphoribosyltransferase protects against ischemic stroke through SIRT1-dependent adenosine monophosphate-activated kinase pathway. Ann Neurol 69: 360-374, 2011.

25. Wang P, Guan YF, Du H, Zhai QW, Su DF and Miao CY: Induction of autophagy contributes to the neuroprotection of nicotinamide phosphoribosyltransferase in cerebral ischemia. Autophagy 8: 77-87, 2012.

26. Wang P, Xu TY, Guan YF, Su DF, Fan GR and Miao CY: Perivascular adipose tissue-derived visfatin is a vascular smooth muscle cell growth factor: role of nicotinamide mononucleotide. Cardiovasc Res 81: 370-380, 2009.

27. Mapanga RF, Joseph D, Symington B, Garson KL, Kimar C, Kelly-Laubscher R and Essop MF: Detrimental effects of acute hyperglycaemia on the rat heart. Acta Physiol (Oxf) 210 546-564, 2014

28. Reynolds JC and Lawner BJ: Management of the post-cardiac arrest syndrome. J Emerg Med 42: 440-449, 2012.

29. Gu W, Li CS, Yin WP, Guo ZJ, Hou XM and Zhang D: Apoptosis is involved in the mechanism of postresuscitation myocardial dysfunction in a porcine model of cardiac arrest. Am J Emerg Med 30: 2039-2045, 2012.

30. Wang S, Radhakrishnan J, Ayoub IM, Kolarova JD, Taglieri DM and Gazmuri RJ: Limiting sarcolemmal $\mathrm{Na}^{+}$entry during resuscitation from ventricular fibrillation prevents excess mitochondrial $\mathrm{Ca}^{2+}$ accumulation and attenuates myocardial injury. J Appl Physiol (1985) 103: 55-65, 2007.

31. Adams JA: Endothelium and cardiopulmonary resuscitation. Crit Care Med 34 (Suppl): S458-S465, 2006.

32. Lant AF, McNabb RW and Noormohamed FH: Kinetic and metabolic aspects of enalapril action. J Hypertens Suppl 2: S37-S42, 1984.
33. Doğan R, Farsak B, Tuncer M and Demirpençe E: Attenuation of ischemia-reperfusion injury by enalapril maleat. Gen Pharmacol 31: 203-208, 1998

34. Montalescot G, Drexler H, Gallo R, Pearson T, Thoenes M and Bhatt DL: Effect of irbesartan and enalapril in non-ST elevation acute coronary syndrome: Results of the randomized, doubleblind ARCHIPELAGO study. Eur Heart J 30: 2733-2741, 2009.

35. Miclescu A, Sharma HS, Martijn C and Wiklund L: Methylene blue protects the cortical blood-brain barrier against ischemia/reperfusion-induced disruptions. Crit Care Med 38: 2199-2206, 2010

36. Hoyer A, Kempfert J, Pritzwald-Stegmann P, Mohr FW and Dhein S: Acute hemodynamic effects of angiotensin-converting enzyme inhibition after prolonged cardiac arrest with Bretschneider's solution. Naunyn Schmiedebergs Arch Pharmacol 387: 1221-1229, 2014

37. Wu B, Lin R, Dai R, Chen $\mathrm{C}, \mathrm{Wu} \mathrm{H}$ and Hong M: Valsartan attenuates oxidative stress and NF- $\kappa \mathrm{B}$ activation and reduces myocardial apoptosis after ischemia and reperfusion. Eur J Pharmacol 705: 140-147, 2013.

38. Kobara M, Tatsumi T, Kambayashi D, Mano A, Yamanaka S, Shiraishi J, Keira N, Matoba S, Asayama J, Fushiki S and Nakagawa M: Effects of ACE inhibition on myocardial apoptosis in an ischemia-reperfusion rat heart model. J Cardiovasc Pharmacol 41: 880-889, 2003.

39. Bjerregaard J and Jaffe RA: Intraoperative cardiac arrest: was it the ACE inhibitor? J Clin Anesth 26: 62-64, 2014.

40. Chua HR, Glassford N and Bellomo R: Acute kidney injury after cardiac arrest. Resuscitation 83: 721-727, 2012.

41. Zhang Y, Boddicker KA, Rhee BJ, Davies LR and Kerber RE: Effect of nitric oxide synthase modulation on resuscitation success in a swine ventricular fibrillation cardiac arrest model. Resuscitation 67: 127-134, 2005.

42. Marques Neto SR, da H Silva A, dos Santos MC, Ferraz EF and Nascimento JH: The blockade of angiotensin AT1 and aldosterone receptors protects rats from synthetic androgen-induced cardiac autonomic dysfunction. Acta Physiol (Oxf) 208: 166-171, 2013.

43. Biwer LA, Broderick TL, Xu H, Carroll $\mathrm{C}$ and Hale TM: Protection against L-NAME-induced reduction in cardiac output persists even after cessation of angiotensin-converting enzyme inhibitor treatment. Acta Physiol (Oxf) 207: 156-165, 2013.

44. Paradis NA, Rose MI and Garg U: The effect of global ischemia and reperfusion on the plasma levels of vasoactive peptides. The neuroendocrine response to cardiac arrest and resuscitation. Resuscitation 26: 261-269, 1993.

45. Soler MJ, Wysocki J and Batlle D: ACE2 alterations in kidney disease. Nephrol Dial Transplant 28: 2687-2697, 2013.

46. Varagic J, Ahmad S, Nagata S and Ferrario CM: ACE2: Angiotensin II/angiotensin-(1-7) balance in cardiac and renal injury. Curr Hypertens Rep 16: 420, 2014.

47. Bernardi S, Toffoli B, Zennaro C, Tikellis C, Monticone S, Losurdo P, Bellini G, Thomas MC, Fallo F, Veglio F, et al: High-salt diet increases glomerular ACE/ACE2 ratio leading to oxidative stress and kidney damage. Nephrol Dial Transplant 27: 1793-1800, 2012

48. Liu R, Qi H, Wang J, Wang Y, Cui L, Wen Y and Yin C: Angiotensin-converting enzyme (ACE and ACE2) imbalance correlates with the severity of cerulein-induced acute pancreatitis in mice. Exp Physiol 99: 651-663, 2014.

49. Hsieh WY, Kuan TC, Cheng KS, Liao YC, Chen MY, Lin PH, Hsu YC, Huang CY, Hsu WH, Yu SY and Lin CS: ACE/ACE2 ratio and MMP-9 activity as potential biomarkers in tuberculous pleural effusions. Int J Biol Sci 8: 1197-1205, 2012. 